\title{
Towards identifying climate resilient poultry birds
}

\begin{abstract}
Among the agriculture sectors, poultry industry contributes substantially to the economy of many countries. Broiler poultry is considered safe enterprise in the changing climate scenario because of the low initial investment as well as the less time for its production. Chicken meat and egg are highly rich in most of the essential micronutrients, which makes them highly demanding to all especially the poor. The desire for chicken meat is rising day by day as it has no religious taboos as compared to red meat. Moreover, it does not compromise in health as it contains low saturated fats and enriched with most of the essential micronutrients. Poultry industry is in leading position among the agricultural and allied sectors. Chicken meat and eggs are the best source of quality protein, and millions of people are craving for it especially who live in poverty. The major advantage of poultry meat and eggs are that there are no religious taboos on their consumption as compared to other livestock products. Poultry products have many positive contributions to the diet of those on low incomes. As well not all meat is seen as healthy as chicken meat and is more affordable than other meats. Poultry meat was considered high quality because of its low saturated fats and enriched essential micronutrients. Climate change associated heat stress has emerged as one of the major constraints of poultry industry particularly in the hot and humid tropics. Birds are deprived of sweat glands and therefore thermoregulation becomes challenging in hot weather, which ultimately compromises their production efficiency and prolonged exposure to heat stress causes mortality of birds. ${ }^{1}$.
\end{abstract}

Volume 7 Issue 3 - 2018

\author{
GDVandana, ${ }^{1,2} \vee$ Sejian' \\ 'ICAR-National Institute of Animal Nutrition and Physiology, \\ India \\ ${ }^{2}$ Academy of Climate Change Education and Research, Kerala \\ Agricultural University, India
}

Correspondence: $\vee$ Sejian, Senior Scientist, ICAR-Nationa Institute of Animal Nutrition and Physiology, Adugodi, Hosur Road, Bangalore-560030, India, Tel +91-9740726 I2I, Fax +91080-257 I 1420,Email drsejian@gmail.com

Received: February 25, 2018 | Published: May 16, 2018

\section{Heat stress as the major factor influencing poultry production}

Climate variation influences poultry production and reduces the production efficiency along with decreased nutrient quality of feed, less water availability and disease emergence and disease-spreading pests which ultimately causes death. Heat stress that emerges as a result of climate change was considered one of the crucial factors which negatively influence the poultry production. Heat stress affects the poultry sector adversely by reducing their feed intake, feed conversion efficiency, growth, meat and egg production and reproductive performance. Thus, poultry birds compromise their production potential to adapt to the changing climate scenario. Although poultry breeds show increase resilience during climatic variation, however, it still impacts both the meat and egg production. Further, Panda ${ }^{2}$ observed that the birds are more sensitive to temperature variation rather than any other climatic factors. It has also been observed that both acute and chronic heat stress negatively influences the poultry production. ${ }^{3}$ Moreover, heat stress also was found to reduce the egg weight, egg shell thickness, eggshell weight, and egg shell percent.

\section{Effect of heat stress on poultry}

Heat stress is a daunting challenge that causes the animal to lose the control over its body to maintain the normal body temperature effectively. ${ }^{4}$ Heat stress becomes severe when the metabolic heat production increases along with the persisting increase in temperature. When the body temperature crosses the thermal comfort zone, various thermoregulatory mechanisms gets activated in the birds to cope with the situation. Heat dissipation becomes even more difficult in poultry as they lack in sweat glands. The deleterious effect of heat stress hampers the growth, egg production, reproduction and immunity. ${ }^{5,6}$ While the poultry industry feels the pressure of heat stress negatively influencing poultry production, simultaneously the demand for poultry meat and egg production are in the increasing trend due to growing human population. Thus, it is very pertinent to implement suitable managemental strategies to minimize the production losses incurred in poultry industry. ${ }^{7,8}$ Although these strategies could ameliorate the condition temporarily, finding a permanent solution to the heat stress associated problems is the need of hour to sustain poultry production in the changing climate scenario. ${ }^{9,10}$

\section{Heat stress and thermoregulation in poultry birds}

Although birds do not have sweat glands, they alter their behavioral and physiological homeostasis seeking thermoregulatory mechanisms to reduce the body temperature. ${ }^{6}$ Further, it was observed that the birds subjected to heat stress significantly increased the water intake and panting mechanisms while significantly lowered their feed intake and body activities. ${ }^{11}$ Birds also have an additional thermoregulatory mechanism using their air sacs which promotes heat exchange between their body and the environment. In addition, birds use their air sacs during panting which helps in surface heat exchange resulting in evaporative heat loss. Also neurological symptoms are exhibited when a bird are dehydrated during exposure to heat stress which causes severe head tilts and inability to perch or fly. All the above discussed consequences due to heat stress may ultimately affect the thermoregulatory mechanisms of the bird which may compromise their production potential.

\section{Thermo-tolerant genes in poultry}

Genetic modification is one such approach that identifies the suitable genes and incorporates to the birds of interest. ${ }^{12,13}$ These genes may include thermo-tolerant genes, disease resistant genes and highly productive genes. Studies have been conducted based on this and have found the superior genes through selective breeding programmes. ${ }^{14}$ 
Poultry industries generally look forward for the highly productive traits to improve their profit. But as production efficiency increased the susceptibility towards heat stress and disease resistance also increased. Eventually, several superior thermo-tolerant genes were identified by the researchers such as the naked neck gene $(\mathrm{Na})$, frizzle gene or the $(\mathrm{F})$ gene, dwarf gene or $(\mathrm{dw})$ gene which made the bird resistant to heat stress through slow and reduced feathering, curling the feather so as the improve the heat dissipation and reduces body size to minimize metabolic heat production. Several other genes were also identified that increase the thermo-tolerance of birds without compromising the production potential. Moreover, heat shock proteins (HSPs) and in particular HSP70 and HSP90 are identified to ideal thermo-tolerant genes for heat stress in poultry. However, breed variations were reported for these results warranting future research activities in these lines. ${ }^{15,16}$

\section{Scope for developing climate resilient poultry}

The technological advancement in biotechnological tools has made tremendous progress in the field of biology to elucidating all hidden intricacies and pathways associated with genetic diversity. ${ }^{11}$ With the applications of advanced biotechnological tools such as Functional genomics, microarray technology, Single Nucleotide Polymorphisms (SNPs), whole genome association studies, whole genome Transcriptome studies and next generation sequencing, it is possible to identify the various transcripts associated with stress pathways. These technologies offers huge scope to identify various transcripts associated with productive, adaptive and disease resistance. Using these technologies it is possible to identify few thousands of genes which impart thermo-tolerance to poultry. Such transcripts can be validated using real time PCR and may be narrowed down to the handful numbers of reliable biological markers which can be incorporated in breeding programs and evolve a new thermo-tolerant breed using marker assisted selection.

\section{Way forward}

Finally, we can conclude that rise in temperature is a foreseeable event that comes along with the current climate scenario. Birds are highly susceptible to the increase in temperature that hampers the poultry production. Therefore, it is very essential to target the gross root of the problems associated with heat stress in poultry. Establishing genetic diversities and identifying new breeding policies for poultry birds are very essential to find a permanent solution for climate change associated production loss. Such an effort must concentrate in striking an appropriate balance between productive, adaptive and disease resistance traits. These efforts might ensure appropriate economic return from the poultry industry in the changing climate scenario.

\section{Acknowledgements}

The authors thank sincerely Director, ICAR-National Institute of Animal Nutrition and Physiology for providing all support for finalising this manuscript.

\section{Conflict of Interest}

The authors declare that there is no any conflict of interest for this particular manuscript.

\section{References}

1. Rath PK, Behura NC, Sahoo SP, et al. Amelioration of Heat Stress for Poultry Welfare: A Strategic Approach. Int J Livest Res. 2015;5(3):1-9.

2. Panda AK, Bhanja SK, Sunder GS. Early post hatch nutrition on immune system development and function in broiler chickens. World's Poult Sci J. 2015;71(2):285-296.

3. Sohail MU, Hume ME, Byrd JA, et al. Effect of supplementation of prebiotic mannan oligosaccharides and probiotic mixture on growth performance of broilers subjected to chronic heat. Poult Sci. 2012;91(9):2235-2240.

4. Adesiji GB, Baba ST, Tyabo IS. Effects of climate change on poultry production in Ondo State, Nigeria. Russian Journal of Agricultural and Socio-Economic Sciences. 2013;14(2):242-248.

5. Ebeid TA, Suzuki T, Sugiyama T. High ambient temperature influences eggshell quality and calbindin-D28k localization of eggshell gland and all intestinal segments of laying hens. Poult Sci. 2012;91(9):2282-2287.

6. Lara LJ, Rostagno MH. Impact of heat stress on poultry production. Animal. 2013;3(2):356-369.

7. Syafwan S, Kwakkel RP, Verstegen MW. Heat stress and feeding strategies in meat-type chickens. World's Poult Sci J. 2011;67(4):653674.

8. Kumari KN, Nath DN. Ameliorative measures to counter heat stress in poultry. Worlds Poult Sci J. 2018;74(1):117-130.

9. Rath PK, Behura NC, Sahoo SP, et al. Amelioration of Heat Stress for Poultry Welfare: A Strategic Approach. Int J of Livest Res. 2015;5(3):19.

10. Pawar SS, Sajjanar B, Lonkar VD, et al. Assessing and mitigating the impact of heat stress on poultry. Adv Anim Vet Sci. 2016;4(6):332-341.

11. Mack LA, Felver-Gant JN, Dennis RL, et al. Genetic variation alter production and behavioral responses following heat stress in 2 strains of laying hens. Poult Sci. 2013;92(2):285-294.

12. Chen ZY, Gan JK, Xiao X, et al. The association of SNPs in Hsp90ßgene 5 ' flanking region with thermo tolerance traits and tissue mRNA expression in two chicken breeds. Mol Biol Rep. 2013;40(9):5295-5306.

13. Bhadauria P, Keshava, Mamgai P, et al. Management of heat stress in poultry production system. ICAR Agricultural Technology Application Research Institute: Ludhiana; 2016.

14. Hoffmann I. Climate change and the characterization, breeding and conservation of animal genetic resources. Anim Genet. 2010;41(1):3246.

15. Felver-Gant JN, Mack LA, Dennis RL, et al. Genetic variations alter physiological responses following heat stress in 2 strains of laying hens. Poult Sci. 2012;91(7):1542-1551.

16. Youssef SF, Yassein DM, El-Bahy NM, et al. A comparative studies among golden montazah, el-salam and fayoumi chickens. 1-response to acute heat stress as early heat conditioning procedure. Egypt Poult Sci. 2014;34(4):1075-1097. 